\title{
CONE-BEAM COMPUTED TOMOGRAPHY IN ASSESSMENT OF REATTACHMENT OF CHISEL FRACTURE OF ANTERIOR TOOTH IN YOUNG PATIENT- A CASE REPORT
}

\author{
Parinitha M. S1, Sowmya H. K²
}

${ }^{1}$ Reader, Department of Conservative Dentistry and Endodontics, JSS Dental College and Hospital, Mysuru, Karnataka, India.

${ }^{2}$ Lecturer, Department of Conservative Dentistry and Endodontics, JSS Dental College and Hospital, Mysuru, Karnataka, India.

HOW TO CITE THIS ARTICLE: Parinitha MS, Sowmya HK. Cone-beam computed tomography in assessment of reattachment of chisel fracture of anterior tooth in young patient- a case report. J. Evolution Med. Dent. Sci. 2019;8(03):230-232, DOI: $10.14260 /$ jemds/2019/50

\section{PRESENTATION OF CASE}

A 13 years old patient reported to department of conservative dentistry and endodontics, JSS dental college and hospital, Mysore, India with chief complaints of pain and broken upper front tooth following trauma $1 \frac{1 / 2}{2}$ months back due to fall from bicycle. Patient complains of moderate to severe continuous pain which aggravates on chewing and bleeding from the same tooth. It subsides on rest/medication. No h/o swelling or fever. Patient claims to be healthy.

Clinical examination revealed upper left central incisor21 with Ellis class III fracture with discolouration and tenderness on percussion. Upper right central incisor-11 showed complicated crown and root fracture (Chisel fracture) with pulpal involvement, tender on percussion with crown vertically split mesiodistally, extending subgingivally. Fractured fragments were immobile. (Fig. 1) Presence of gingival bleeding on probing. A periapical radiographic examination revealed fracture line extending 3- to 4-mm cervically from cementoenamel junction. Completely formed root with pdl space widening present. (Fig. 2)

Trauma is the most common reason for upper tooth fracture seeking dental care. Injuries to upper front deciduous and permanent dentition are among the most common types of trauma to occur in the maxillofacial region 1 and occurs most commonly in boys than in girls because of their active involvement in sports. ${ }^{2-4}$

Crown root fracture account for up to $5 \%$ of all traumatic injuries $^{5}$ and maxillary incisor up to $37 \%$, this is mainly because of their anterior position in the arch and protrusion caused by the eruptive pattern.6,7

For managing crown root fracture with little or no violation of the biologic width when coronal fragment is available one of the best options is reattachment of the fractured fragment. Reattachment of the fractured tooth fragment offers better aesthetics, tooth wear is at a rate similar to that of the adjacent teeth, consumption of time is less and a positive response from the patient for preservation of natural tooth structure. Reattachment of tooth fragment using modern adhesive technique and restorative procedure showed the long-term clinical success. ${ }^{8}$

'Financial or Other Competing Interest': None.

Submission 06-12-2018, Peer Review 07-01-2019,

Acceptance 14-01-2019, Published 21-01-2019.

Corresponding Author:

Dr. Sowmya HK,

Department of Conservative Dentistry and Endodontics,

JSS Dental College and Hospital,

JSS Academy of Higher Education and Research,

JSS Medical Institutions Campus,

Sri Shivarathreeshwara Nagara,

Mysuru-570015, Karnataka, India.

E-mail: sowmyahk84@gmail.com

DOI: $10.14260 /$ jemds $/ 2019 / 50$
Cone Beam Computed Tomography (CBCT) is an extraoral imaging system mainly designed for three-dimensional imaging which is the gold standard; it produces clear images with higher resolution and was used in this case to assess the proper seal of the fractured fragment. ${ }^{9}$

\section{DIFFERENTIAL DIAGNOSIS}

- Chronic Irreversible Pulpitis

- Acute Alveolar Abscess associated with Trauma

- Chronic Apical Periodontitis

- Pulp Necrosis.

\section{CLINICAL DIAGNOSIS}

Chronic Irreversible Pulpitis with Apical Periodontitis

\section{DISCUSSION OF MANAGEMENT}

Based on clinical examination and radiographic findings, a diagnosis of chronic irreversible pulpitis with apical periodontitis was made and a non-surgical endodontic treatment and reattachment of the fracture fragments using a nano composite was performed.

Local anesthesia (Lignox A, Indoco Remedies Ltd., Gujarat, India) was administered for 11 and 21 access cavity was prepared from lingual approach, Pulp was extirpated with barbed broach (Mani), working length was established with the help of electronic apex locator (Propex II Apex Locator, Dentsply) and confirmed with radiograph, followed by cleaning and shaping done using ProTaper (Dentsply), with the master apical file being F5. Irrigants like $2.5 \%$ sodium hypochlorite and saline solution were used during the preparation alternately. The root canal was dried with paper points and calcium hydroxide (RC Cal, prime dental product pvt ltd) closed dressing given for 11 and for 21, formocresol closed dressing given and access cavities closed with reinforced zinc oxide eugenol.

On the second visit, tooth was asymptomatic, temporary restoration and calcium hydroxide dressing was removed, both canals were then obturated with combination of lateral and vertical condensation using Guttapercha and AH Plus sealer (Maillefer, Dentsply, Konstanz, Germany). Access cavity temporarily closed with reinforced zinc oxide eugenol. (Fig. 3). After completion of Root canal treatment of both the central incisors, gingivectomy was performed for 11 .

After 7 days, post obturation coronoradicular restoration and reattachment of the fractured fragments were done by using bonding system (Single Bond Universal, 3M ESPE, Multi-Purpose Adhesive) and nanocomposite adhesive restorative material (Filtek Z350 XT, 3M ESPE). (Fig. 4) CBCT was taken for confirmation of proper seal of fracture fragment. (Fig. 5) 
Recalled after 5 months and 1-year (Fig. 6 \& 7) patient was asymptomatic.
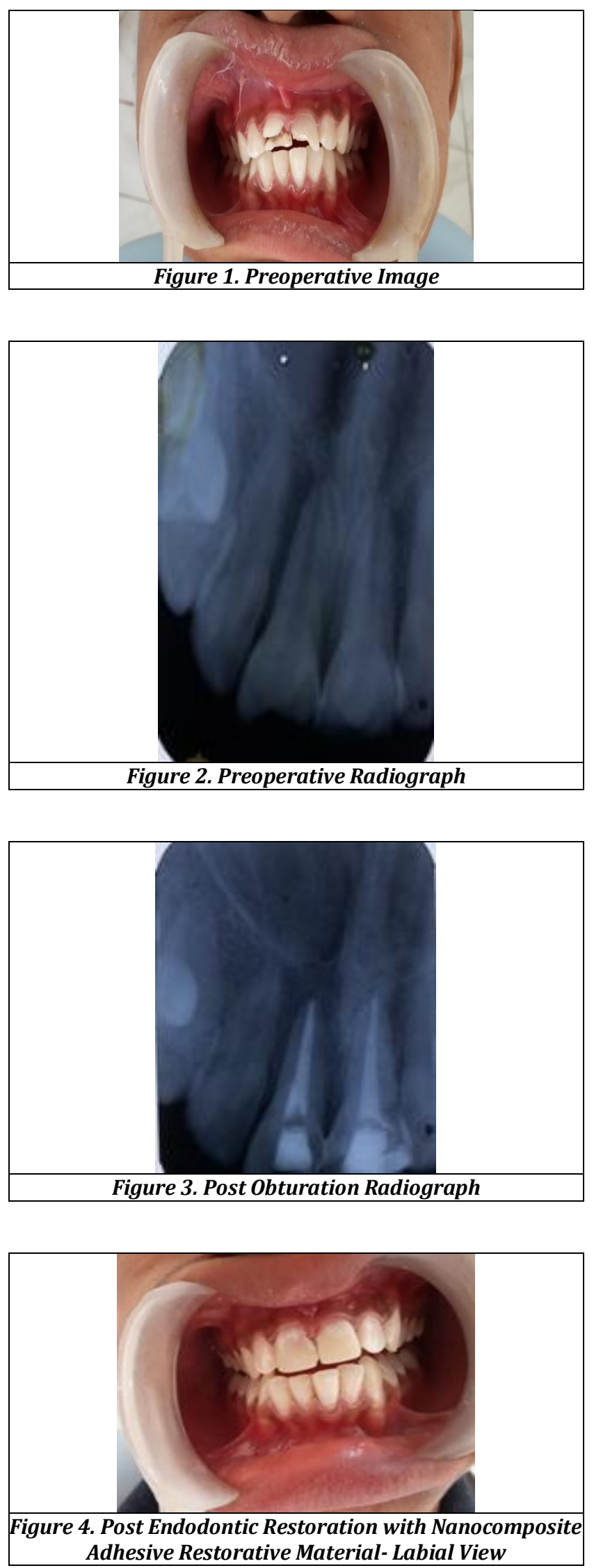

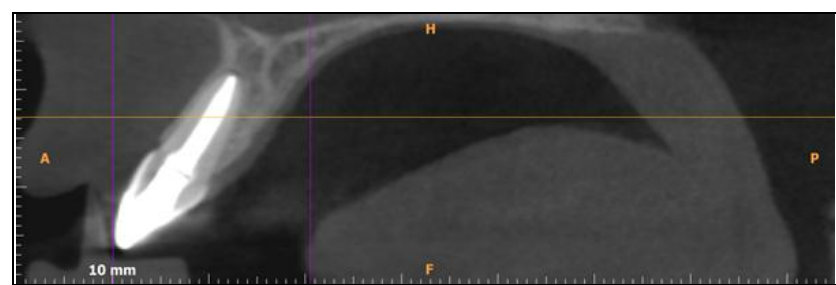

Figure 5. Postoperative CBCT Image of Reattached Fracture Fragment
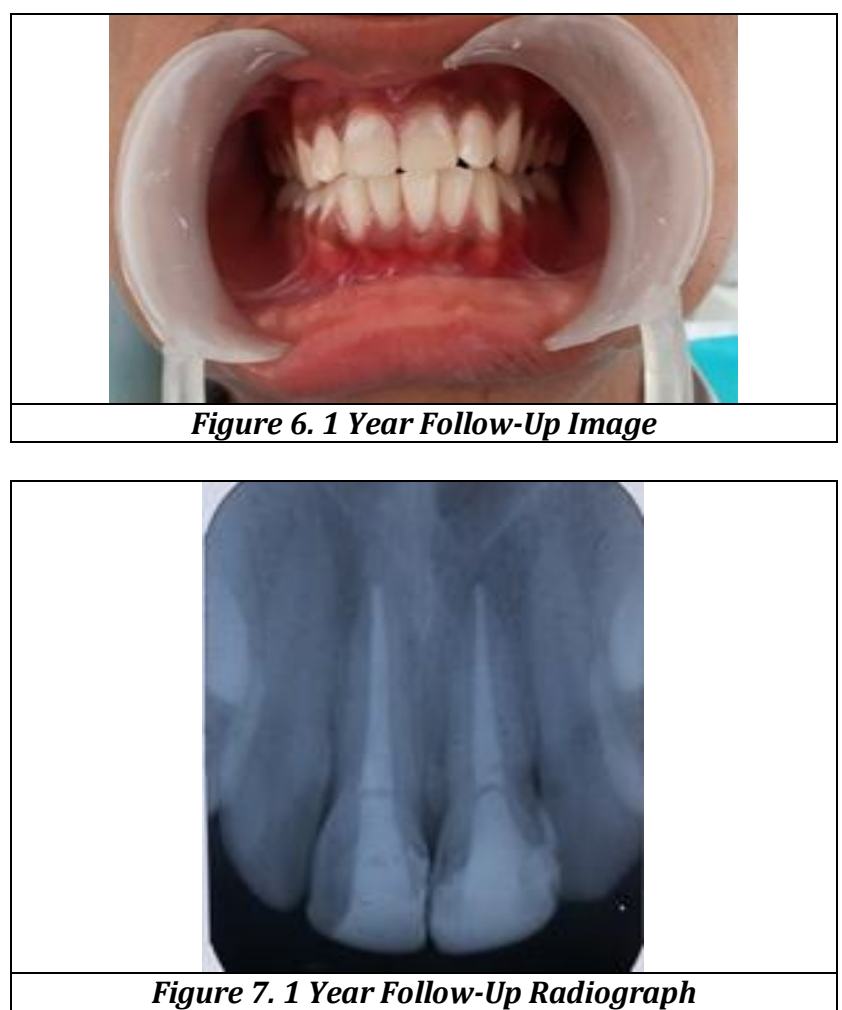

\section{PATHOLOGICAL DISCUSSION}

Crown-root fractures are the most common among children due to trauma. These type of fracture can be managed including the following factors like pulp involvement, alveolar bone fracture, extent \& pattern of fracture, biologic width involvement, injuries to soft tissue, presence/absence of fractured tooth fragment, occlusion, aesthetics, stages of root development and secondary traumatic injuries. ${ }^{10,11}$ such fractures have horizontal impact extending below the gingival margin involving enamel, dentin \& cementum and represents $5 \%$ of all dental injuries. They can be complicated or uncomplicated fractures depending on the presence of pulpal involvement which involves the biologic width of the tooth. 12

The reattachment of coronal fragment is one of the best method to restore the fragment's natural tooth structure by maintaining occlusal alignment, shape of tooth, surface texture, colour and contour of the tooth. ${ }^{13}$ It get rids the patient worry, with this approach which is comparatively simple, atraumatic and inexpensive with minimal wear of restorative materials and offers superior aesthetic \& functional results in an appointment and maintaining the periodontal attachment. 14

With the development in adhesive technology, the clinician can achieve excellent outcome with reattachment of fractured tooth fragments with properly assess and manages the biological factors, materials and techniques. 
Clinicians can achieve conservative, aesthetics and restore the function with reattaching the tooth fragments by reinforcing with advanced materials and techniques. The space present in the pulp chamber by endodontic therapy with minimal tooth preparation provides predictable outcomes. 15

In the present study the young patient with fractured fragment reattachment is an excellent conservative approach for restoration with the available fragment. Reattachment of fractured tooth using recent adhesive system and nanocomposites achieved functional and aesthetic success with clinical test and long-term follow up have been reported.

CBCT was used as it is more precise than periapical radiograph in confirming the reattachment of the tooth fragment. With this coronal and axial view of the maxillary anterior were readily produced, confirming the reattachment.

Fractured tooth fragments bonding helps in-

- Conservative approach.

- Restoration of biological function.

- Cost effectiveness.

- Maintaining Aesthetics and

- Reducing time duration.

The reattachment of fractured fragments of teeth is an appropriate technique that restores function and aesthetics in a very biological approach with the advanced materials and it can be considered first line of treatment with coronal fractures of the anterior teeth, especially in younger patients.

\section{REFERENCES}

[1] Sowmya HK, Jayahari NK, Subash TS, et al. An esthetic approach to retain fracture tooth fragment. J Int Clin Dent Res Organ 2014;6:46-9.

[2] American Academy on Pediatric Dentistry Council on Clinical Affairs. Guideline on management of acute dental trauma. Pediatr Dent 2008-2009;30(Suppl 7):175-83.

[3] Filho SPC, Quagliatto PS, Simamoto PC Jr, et al. Dental trauma: restorative procedures using composite resin and mouthguards for prevention. J Contemp Dent Pract 2007;8(6):89-95.
[4] Forsberg CM, Tedestam G. Etiological and predisposing factors related to traumatic injuries to permanent teeth. Swed Dent J 1993;17(5):183-90.

[5] Naudi AB, Fung DE. Tooth fragment reattachment in multiple complicated permanent incisor crown-root fractures - a report of two cases. Dent Traumatol 2008;24(2):248-52.

[6] Tennery TN. The fractured tooth reunited using the acid-etch bonding technique. Tex Dent J 1978;96(8):16-7.

[7] Reis A, Loguercio AD, Kraul A, et al. Reattachment of fractured teeth: a review of literature regarding techniques and materials. Oper Dent 2004;29(2):22633.

[8] Macedo GV, Diaz PI, De O Fernandes CA, et al. Reattachment of anterior teeth fragments: a conservative approach. J Esthet Restor Dent 2008;20(1):5-20.

[9] Adibi S, Zhang W, Servos T, et al. Cone beam computed tomography in dentistry: What dental educators and learners should know? Journal of Dental Education 2012;76(11):1437-42.

[10] Andreasen JO, Andreasen FM, Andersson L. In: Textbook and Color atlas of traumatic injuries to the teeth. $4^{\text {th }}$ edn. Blackwell Publishing Company, 2007.

[11] Olsburgh S, Jacoby T, Krejci I. Crown fractures in the permanent dentition: pulpal and restorative considerations. Dent Traumatol 2002;18(3):103-15.

[12] Kulkarni VK, Sharma DS, Banda NR, et al. Clinical management of a complicated crown-root fracture using autogenous tooth fragment: a biological restorative approach. Contemporary Clinic Dent 2013;4(1):84-7.

[13] Badami V, Reddy SK. Treatment of complicated crownroot fracture in a single visit by means of re-bonding. J Am Dent Assoc 2011;142(6):646-50.

[14] Arhun N, Ungor M. Re-attachment of a fractured tooth: a case report. Dent Traumatology 2007;23(5):322-6.

[15] Amir E, Bar-Gil B, Sarnat H. Restoration of fractured immature maxillary central incisor using the crown fragments. Pediatr Dent 1986;8(4):285-8. 